\title{
BMJ Open Differences in the pregnancy gestation period and mean birth weights in infants born to Indian, Pakistani, Bangladeshi and white British mothers in Luton, UK: a retrospective analysis of routinely collected data
}

Rebecca Garcia, ${ }^{1}$ Nasreen Ali, ${ }^{1}$ Andy Guppy, ${ }^{2}$ Malcolm Griffiths, ${ }^{3}$ Gurch Randhawa ${ }^{1}$

To cite: Garcia R, Ali N, Guppy A, et al. Differences in the pregnancy gestation period and mean birth weights in infants born to Indian, Pakistani, Bangladeshi and white British mothers in Luton, UK: a retrospective analysis of routinely collected data. BMJ Open 2017;7:e017139. doi:10.1136/ bmjopen-2017-017139

- Prepublication history for this paper is available online. To view these files please visit the journal online (http://dx.doi. org/10.1136/bmjopen-2017017139).

Received 3 April 2017 Revised 7 June 2017 Accepted 19 June 2017

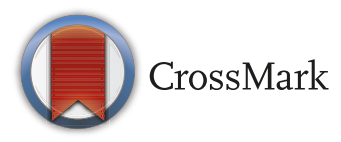

${ }^{1}$ The Institute For Health Research, University of Bedfordshire, Bedfordshire, UK ${ }^{2}$ The Institute for Applied Social Sciences, University of Bedfordshire, Bedfordshire, UK ${ }^{3}$ Luton \& Dunstable University Hospital NHS Foundation Trust, Luton, UK

Correspondence to

Rebecca Garcia;

Rebecca.Garcia@beds.ac.uk

\section{ABSTRACT}

Objective To compare mean birth weights and gestational age at delivery of infants born to Indian, Pakistani, Bangladeshi and white British mothers in Luton, UK. Design Retrospective analysis using routinely recorded secondary data in Ciconia Maternity information System, between 2008 and 2013.

Setting Luton, UK.

Participants Mothers whose ethnicity was recorded as white British, Bangladeshi, Pakistani or Indian and living in Luton, aged over 16, who had a live singleton birth over 24 weeks of gestation were included in the analysis $(n=14871)$.

Outcome measures Primary outcome measures were mean birth weight and gestational age at delivery. Results After controlling for maternal age, smoking, diabetes, gestation age, parity and maternal height and body mass index at booking, a significant difference in infants' mean birth weight was found between white British and Indian, Pakistani and Bangladeshi infants, $F(3$, $12287)=300.32, p<0.0001$. The partial Eta-squared for maternal ethnicity was $\eta^{2}=0.067$. The adjusted mean birth weight for white British infants was found to be $3377.89 \mathrm{~g}(95 \% \mathrm{Cl} 3365.34$ to 3390.44$)$; Indian infants, $3033.09 \mathrm{~g}$ (95\% Cl 3038.63 to 3103.55$)$; Pakistani infants, $3129.49 \mathrm{~g}(95 \% \mathrm{Cl} 3114.5$ to 3144.48$)$; and Bangladeshi infants, $3064.21 \mathrm{~g}(95 \% \mathrm{Cl} 3041.36$ to 3087.06$)$. There was a significant association in preterm delivery found in primipara Indian mothers, compared with Indian mothers (Wald $=8.192$, df $1, p<0.005$ ).

Conclusions Results show important differences in adjusted mean birth weight between Indian, Pakistani, Bangladeshi and white British women. Moreover, an association was found between primipara Indian mothers and preterm delivery, when compared with Pakistani, Bangladeshi and white British women.

\section{INTRODUCTION}

Low birth weight (LBW) is a significant contributory factor for increased risk of infant mortality and morbidity ${ }^{1}$ and has health

\section{Strengths and limitations of the study}

- This study uses retrospective routinely collected data over 6 years providing a large sample size, $(n=14871)$, providing more generalisable results.

- This paper adds to the sparse existing evidence that examines heterogeneity in birth weight and gestation age at delivery between women from South Asia in the UK.

- This study was unable to accurately identify socioeconomic measures and subsequently control for, and analyse these, understanding that socioeconomic factors may have contributed to the study results.

consequences extending into adulthood. ${ }^{2}$ It is also a recognised proxy for maternal health. ${ }^{34}$ LBW is defined as birth weight of less than $2500 \mathrm{~g}$ at birth. ${ }^{5}$ The rather arbitrary figure of $2500 \mathrm{~g}$ was determined by WHO, as birth weight less than this shows a substantially increased mortality rate. ${ }^{7}$ Birth weight of $1500 \mathrm{~g}$ is classified as very low birth weight (VLBW) and has an exponentially higher mortality rate. ${ }^{8}$ VLBW/LBW may be a consequence of a number of mediating factors including preterm birth (PTB), ${ }^{9}$ small for gestational age ${ }^{610}$ and intrauterine growth restriction (IUGR), whereby the normal development of the fetus is hampered. ${ }^{11}$

Existing evidence shows that South Asian women typically give birth to infants of lower birth weights than white British (WB) women $^{12}{ }^{13}$ with babies on average being 230-350 g lighter. ${ }^{14-16}$ Typically, statistics in the UK use aggregated data from Indian, Pakistani and Bangladeshi infants/mothers, as 'South Asian', ${ }^{17-19}$ obscuring nuances between each ethnic group, ${ }^{20}$ or have been 
reported as 'South Asian' when only one specific ethnic group is reported (eg, Pakistani) ${ }^{1619}$ Research documents a host of maternal, infant and social factors contributing to LBW, for example, gestational age at delivery, ${ }^{21}$ poor maternal nutrition, ${ }^{22}$ smoking, ${ }^{23}$ maternal underweight, ${ }^{24}$ socioeconomic status ${ }^{5}$ and maternal depression. ${ }^{25}$ Studies have also assessed differences in maternal country of birth on birth weights ${ }^{1426}$ and between generations. ${ }^{41427}$

Lighter birthweight infants in South Asian infants are well documented. ${ }^{1214}{ }^{19}$ Margetts and colleagues ${ }^{4}$ defined South Asian mothers originating from the Indian subcontinent using either maternal place of birth, for example, India, Pakistan or Bangladesh (as first generation), or UK born (as second generation). They reported differences in the mean birth weights of first-generation Indian (3077g), Bangladeshi (3161g) and Pakistani (3235g) infants. The same trend was observed in the Millennium Cohort Study (MCS) whereby Indian mothers have the lightest infants and Pakistani mothers had the heaviest. ${ }^{12}$ Conversely, Leon and Moser ${ }^{14}$ found that Bangladeshi infants were the lightest, while consistent with the other studies, Pakistani infants were heaviest among the infants born to South Asian mothers.

Margetts $e t a l^{4}$ restricted their analyses to births after 37 weeks, which eliminated trends accounted for by gestational age, in addition to aggregating maternal ethnicity to assess for differences between maternal generations (ie, born in the Indian subcontinent classified as first generation or UK classified as second generation). While MCS showed that Pakistani mothers had a lower rate of preterm delivery, the study showed that Indian mothers had a higher rate. ${ }^{12}$ Moreover, national figures for 2012 showed that Bangladeshi mothers had higher rate of infant mortality; conversely, Pakistani and Indian mothers had higher preterm delivery rates, ${ }^{28}$ while Pakistani mothers had a higher preterm delivery mortality rate, when compared with British women. ${ }^{29}$ Together, this demonstrates discreet differences between birth patterns of women of South Asian ethnicity in the UK.

LBW is a complex research area that has been hampered by inconsistent research methods and outcome measures such as mean birth weight ${ }^{414}$ or weight frequencies ${ }^{30} 31$ or aggregated ethnicities, ${ }^{4}$ thereby making comparison between studies difficult. It is important to tease out the nuances of low birth weight trends between Indian, Pakistani and Bangladeshi mothers in order to uncover modifiable factors before specific tailored interventions are developed ${ }^{32}$ and by identifying differences in birth weight and gestational age at delivery between Indian, Pakistani and Bangladeshi and WB women in Luton, England. This paper makes a contribution to this research area.

\section{METHODS}

Routinely collected retrospective data from Ciconia Maternity information System (CMiS) from the Luton and Dunstable University Hospital were used. The CMiS database is a clinical information system used in some maternity departments in the UK to record all births (ie, hospital and home). Purposive sampling of women aged over 16 and all birth outcomes (ie, live and perinatal mortality), who gave birth between January 2008 and December 2013, residing in specified postcode areas were included.

\section{Variables}

Outcome variables of mean birth weight and preterm gestation age were used. Known confounders were maternal age $(16-20,21-25,26-30,31-35,36-40,>40)$, smoking (binary variable smoker/non-smoker), parity, diabetes (binary variable), gestation age (binary variable $<24$ weeks of gestation excluded, 24-37 weeks of gestation and after 37 weeks of gestation) and maternal height and body mass index (BMI) at booking were included and controlled. ${ }^{31}$ 33-36 Maternal hypertension is associated with increased risks of adversity in pregnancy for mother and fetus, including placental problems and IUGR. ${ }^{37}$ However, the CMiS data (for WB, Indian, Pakistani and Bangladeshi records) only had 12 data entries recorded for maternal hypertension; the reasons for the lack of data are unknown, and therefore to avoid error, the variable was excluded from this analysis.

Recording ethnicity in the National Health Service (NHS) is a mandatory requirement, and staff is required to ask women for their self-ascribed ethnicity, according to the 2001 census categories ${ }^{38}$ Ethnicity is a self-defined construct, which incorporates culture, religion, shared language and ancestry. ${ }^{39}$ Consequently, within this study, maternal country of birth, length of residency or generational status was not ascertained, but the broader self-classification of ethnicity as recorded in NHS is used for analysis. Cases with missing data were excluded.

\section{Statistical analysis}

Analyses were conducted using IBM Statistics Package for the Social Sciences V21. The raw data contained data on all ethnicities ( $n=21264)$; however, for the purposes of this paper, data were selected for only WB, Pakistani, Indian and Bangladeshi outcomes, and statistics were conducted on live singleton infants only who were delivered after 24 weeks (reported as adjusted means) ( $\mathrm{n}=14871$ ).

Frequency counts and percentages were calculated. Analysis of variance (ANOVA) was used to determine whether there were any significant differences in birth weight between the four ethnic groups and each confounder variable (ie, maternal age, smoking status, diabetes, gestation age at delivery, parity and maternal height and BMI). Means, SE and 95\% CI were calculated for each ethnic group. An analysis of covariance (ANCOVA) was conducted to ascertain birthweight difference between ethnic groups and to control for confounding variables with birth weight as the outcome variable. Bonferonni post hoc analysis was used to determine where significant differences were, if any. Pearson $\chi^{2}$ test for association and adjusted standardised residual were used to test for 
associations between maternal ethnicity and gestation age at delivery. However, to account for the effect of parity on gestation age at delivery, a filter variable was created to use only primipara (others were treated as missing), for the calculation of preterm delivery. Multiple regressions were used to determine variance explained of smoking on birth weight, and logistic regression was used to determine whether ethnicity increased the OR for PTB.

Routinely collected secondary data were provided to the research team in a non-identifiable form. Ethics approval was therefore not required from National Research Ethics Service (NRES) but was obtained from the University of Bedfordshire Research Ethics Committee (March 2014). Scrutiny from the hospital's information governance manager ensured adherence to patient confidentiality and data protection before de-identified routinely collected data were provided.

\section{RESULTS}

Our results focus on mothers of WB, Indian, Pakistani and Bangladeshi ethnicity. There were a total 15211 births for the years 2008-2013, of which 14871 were recorded in CMiS as live singleton deliveries, which were delivered after 24 weeks of gestation. The frequencies and percentages of women recorded as being smokers, diagnosed with diabetes (type 1, type 2 and gestational diabetes), maternal BMI at booking and gestational age at delivery are shown by ethnic group (table 1), as recognised confounders to infant weight. A series of ANOVAS found significant differences between birth weight and each ethnicity for each confounding variable and these shown in table 1. There were 69 missing entries for diabetes $(0.5 \%)$ and 29 cases of smoking data missing $(0.2 \%)$ and 8 missing entries for BMI $(0.05 \%)$. The cohort mean birth weight is $3214 \mathrm{~g}$.

An ANCOVA was used to determine the effect of maternal ethnicity on birth weight and adjusting confounders to birth weight. Birth weight is reported as unadjusted and adjusted mean(s) and shown for each maternal ethnicity (table 2). The adjusted mean birth weight results found that Bangladeshi mothers had the lightest mean birth weights (3068.01 g) compared with WB mothers who delivered infants with a mean birth weight of $3375.66 \mathrm{~g}$, showing a difference of $307.65 \mathrm{~g}$. The adjusted results showed a significant difference in mean infant birth weight by maternal ethnicity; $\mathrm{F}(3$,

Table 1 Cohort frequencies and percentages of live singleton deliveries, age, smokers, diabetes, BMI and gestation for 20082013

\begin{tabular}{|c|c|c|c|c|c|c|}
\hline & & White British & Indian & Pakistani & Bangladeshi & Total \\
\hline \multicolumn{2}{|c|}{$\begin{array}{l}\text { Live singletons } \\
N(\%)\end{array}$} & $6862(46.1)$ & $1710(24.8)$ & 5025 (33.8) & 2013 (13.5) & 14871 \\
\hline \multicolumn{2}{|c|}{$\mathrm{p}$} & $<0.001$ & 0.370 & $<0.001$ & $<0.001$ & \\
\hline \multirow{6}{*}{$\begin{array}{l}\text { Maternal age } \\
\text { N (\%) }\end{array}$} & $16-20$ & 1006 (14.6) & $15(1.5)$ & $217(4.3)$ & $91(4.5)$ & $1329(8.9)$ \\
\hline & $21-25$ & $1710(24.8)$ & $200(20.5)$ & $1486(29.3)$ & $581(28.5)$ & 3977 (26.5) \\
\hline & $26-30$ & $2010(29.1)$ & 407 (41.7) & 1859 (36.6) & 801 (39.3) & 5077 (33.9) \\
\hline & $31-35$ & 1487 (21.5) & 261 (26.8) & $1099(21.6$ & $431(21.2)$ & 3278 (21.9) \\
\hline & $36-40$ & $599(8.7)$ & $79(8.1)$ & $378(7.4)$ & $123(6)$ & $1179(7.9)$ \\
\hline & $40+$ & $97(1.4)$ & $13(1.3)$ & $38(0.7)$ & $9(0.4)$ & $157(1)$ \\
\hline \multicolumn{2}{|l|}{$p$} & $<0.001$ & $<0.001$ & $<0.001$ & $<0.001$ & \\
\hline \multicolumn{2}{|l|}{$\begin{array}{l}\text { Smokers } \\
\mathrm{N}(\%)\end{array}$} & 1490 (21.6) & $19(2)$ & $73(1.4)$ & $18(0.9)$ & $1600(10.7)$ \\
\hline \multicolumn{2}{|l|}{$p$} & 0.001 & 0.002 & 0.031 & 0.016 & \\
\hline \multicolumn{2}{|l|}{ Diabetic } & $54(0.8)$ & $14(1.4)$ & 117 (2.3) & $18(0.9)$ & $253(1.7)$ \\
\hline \multicolumn{2}{|l|}{$p$} & 0.11 & 0.08 & 0.54 & 0.39 & \\
\hline \multirow{4}{*}{$\begin{array}{l}\text { BMI } \\
\text { N (\%) }\end{array}$} & $19-24.9$ & 2518 (36.5) & $424(43.5)$ & $1624(32)$ & 757 (37.2) & $5323(35.5)$ \\
\hline & $25-29.5$ & $1710(24.6$ & 262 (26.9) & 1297 (25.6) & $546(26.8)$ & 3815 (25.5) \\
\hline & $30-39.9$ & 1146 (16.6) & $79(8.1)$ & 794 (15.6) & $226(11.1)$ & 2245 (15) \\
\hline & $40-50$ & $182(2.6)$ & $8(0.8)$ & $80(1.6)$ & $24(1.2)$ & $294(2)$ \\
\hline \multicolumn{2}{|l|}{$p$} & $<0.001$ & 0.07 & $<0.001$ & $<0.001$ & \\
\hline \multirow{2}{*}{$\begin{array}{l}\text { Gestation (in } \\
\text { weeks) } \\
\mathrm{N}(\%)\end{array}$} & $24-37$ & $451(6.5)$ & $74(7.6)$ & $308(6.1)$ & $124(6.1)$ & 957 (6.4) \\
\hline & $37+$ & 6447 (93.5) & 899 (92.4) & 4757 (93.9) & 1908 (93.6) & 14011 (93.6) \\
\hline \multicolumn{2}{|l|}{$p$} & $<0.001$ & $<0.001$ & $<0.001$ & $<0.001$ & \\
\hline
\end{tabular}

BMI, body mass index. 
Table 2 Unadjusted and adjusted mean birth weight for 2008-2013 by maternal ethnicity

\begin{tabular}{lllllrcr}
\hline $\begin{array}{l}\text { Maternal } \\
\text { ethnicity }\end{array}$ & N & $\begin{array}{l}\text { Unadjusted } \\
\text { mean }\end{array}$ & SE & Adjusted mean* & SE & Lower bound & Upper bound \\
\hline White British & 5853 & 3352.51 & 5.13 & 3375.66 & 6.43 & 3363.07 & 3388.26 \\
\hline Indian & 840 & 3045.53 & 4.64 & 3073.08 & 16.56 & 3040.62 \\
Pakistani & 4013 & 3164.89 & 4.71 & 3130.71 & 7.65 & 3115.72 & 3145.71 \\
\hline Bangladeshi & 1689 & 3080.75 & 5.14 & 3068.01 & 11.7 & 3045.09 \\
\hline
\end{tabular}

*Adjusted for maternal age, smoking status, diabetes, gestation age at delivery and maternal height, body mass index and parity.

14781) $=310.23, \mathrm{p}<0.001$. The partial Eta-squared for maternal ethnicity was $\eta^{2}=0.067$.

The covariates of BMI $(\mathrm{F}(1,12384)=242.43$, $\mathrm{p}<0.005$, partial $\left.\eta^{2}=0.019\right)$, maternal smoking $(\mathrm{F}(1$, 12384) $=212.78, \quad \mathrm{p}<0.005$, partial $\left.\eta^{2}=0.017\right)$, maternal height $\left(\mathrm{F}(1,12384)=14.57, \mathrm{p}<0.001\right.$, partial $\left.\eta^{2}=0.001\right)$ and parity $(\mathrm{F}(1,12384)=33.07, \mathrm{p}<0.005$, partial $\eta$ $\left.{ }^{2}=0.003\right)$ had a significant effect on birth weight, while the covariates of maternal diabetes and age were not significant in this analysis.

Bonferroni post hoc analysis revealed that adjusted mean birth weight was statistically significantly lower in Indian $(\mathrm{M}=3073.08, \mathrm{SE}=17.83)$, Pakistani $(\mathrm{M}=3130.71, \mathrm{SE}=10.74)$ and Bangladeshi $(\mathrm{M}=3068.01, \mathrm{SE}=13.62)$ compared with WB infants $(\mathrm{M}=3375.66, \mathrm{SE}=6.43)$, a mean difference of $-302.58 \mathrm{~g}$ (95\% CI 255.53 to 349.62 ), $\mathrm{p}<0.005$, (Indian); $-307.65 \mathrm{~g}$ (95\% CI 271.72 to 343.59), $\mathrm{p}<0.005$ (Bangladeshi); and -244.95 (95\% CI 217.84 to 272.06), $p<0.005$ (Pakistani). Moreover, differences in adjusted mean birth weight were found between Indian and Pakistani infants $(-57.63 \mathrm{~g}$ (95\% CI -105.85 to -9.41$), \mathrm{p}<0.01)$ and Pakistani and Bangladeshi infants $(62.7 \mathrm{~g}$ (95\% CI 26.44 to 98.96), $\mathrm{p}<0.005)$, but no significance was found between the adjusted mean birth weight of Indian and Bangladeshi infants.

As smoking is a recognised contributor for LBW, multiple regressions were conducted to determine the variance of smoking on birth weight. The assumptions for multiple regressions were checked and satisfied. The $\mathrm{R}^{2}$ for the model was 0.046 . Smoking was found to statistically predict lower birth weight $\mathrm{F}(2,15174)=365.85$, $\mathrm{p}<0.001$ (see table 3).

Next, multiple regression was conducted to establish variance of PTB on birth weight, by ethnicity. $\mathrm{R}^{2}$ varied according to ethnicity between 0.222 and 0.288 ; the cohort model was $0.26, \mathrm{R}^{2}$ for Bangladeshi infants was $0.236, \mathrm{R}^{2}$ for Pakistani infants was $0.234, \mathrm{R}^{2}$ for WB infants 0.288 and $\mathrm{R}^{2}$ for Indian infants was 0.222 .

\begin{tabular}{|c|c|c|c|}
\hline Variable & B & $\mathrm{SE}_{\mathrm{B}}$ & $\boldsymbol{\beta}$ \\
\hline Smoking status & -242.25 & 16.23 & -0.125 \\
\hline Ethnicity & -50.52 & 1.93 & -0.219 \\
\hline
\end{tabular}

$\mathrm{B}$, unstandardised regression coefficient; $\mathrm{SE}_{\mathrm{B}}$, SE error of the coefficient; $\beta$, standardised coefficient.
ANOVA was significant in all ethnic groups. ANOVA for $\mathrm{WB}$ infants was $\mathrm{F}(1,7015)=2831.84, \mathrm{p}<0.001$; Indian infants, $\mathrm{F}(1,989)=282.25$, $\mathrm{p}<0.001$; Pakistani infants, $\mathrm{F}(1$, $1539)=1844.75, \mathrm{p}<0.001$; and Bangladeshi infants, $\mathrm{F}(1$, $2055)=634.52, p<0.001$.

A binary logistic regression procedure was used to examine the relationship between ethnicity and PTB. An overall significant relationship was observed $\left(\chi^{2}(7.85)=\mathrm{df}\right.$ $3, \mathrm{p}<0.05)$. Using the WB category as a comparison, it was found that the Indian ethnic group was significantly over-represented in terms of PTB ( $W=8.192$, df 1 , $\mathrm{p}<0.005)$. The $\operatorname{Exp}(\mathrm{B}) / \mathrm{OR}$ value was 1.621 (95\% CI 1.165 to 2.258 ).

\section{DISCUSSION}

The aim of this paper was to identify differences in birth weight and gestation age at delivery between Indian, Pakistani and Bangladeshi and WB women. Differences between the mean birth weights of Indian, Pakistani, Bangladeshi and WB infants were found, in addition to an association between preterm delivery in primipara Indian mothers. The results showed that there was a difference of $307.65 \mathrm{~g}$ between WB and Bangladeshi infants. This is consistent with previous results showing that South Asian infants are 230-250 g lighter. ${ }^{14-16}$ Moreover, a small difference ranging from 57.63 to $62.7 \mathrm{~g}$ was also identified between Indian, Bangladeshi and Pakistani infants, although this marginal difference is likely not be clinically useful.

The results showed that Indian infants had the lightest unadjusted mean birth weights, followed by Bangladeshi, Pakistani and WB infants, respectively. However, after controlling for known confounders, Bangladeshi infants were found to have the lightest mean birth weight. Not unexpectedly, maternal smoking, maternal height, BMI and parity showed a significant independent contribution to the outcome of infant birth weight. Furthermore, an association was found between primipara Indian mothers and preterm delivery, within this cohort.

Leon and Moser $^{14}$ also found that Bangladeshi infants were the lightest, compared with Indian, Pakistani or WB infants. On the other hand, $\mathrm{MCS}^{12}$ calculated birth weight gestation age at delivery using self-reported data and found that the unadjusted mean birth weight was lightest in Indian infants, followed 
by Bangladeshi, Pakistani and $\mathrm{WB}$, respectively. Furthermore, the adjusted mean calculations showed a number of different findings according to the variables controlled; maternal and infant factors (ie, gestation age, parity, maternal height and weight and antenatal complications) found that Pakistani infants were lightest, whereas controlling for behavioural factors (ie, antenatal care, smoking and drinking) and socioeconomic factors (ie, household income, education status, occupation status, single parentage and housing tenure) showed that Indian infants were lightest. Margetts et $a l^{4}$ results also showed that infants delivered to mothers born in India had lighter infants, while Pakistani-born mothers had heavier infants; however, their results were only adjusted for generation status, and therefore, the mean weight reported in the paper is unadjusted.

Taken together, this is suggestive that birth weight might be sensitive to different combinations of mediators, which may vary according to maternal ethnicity, an important point for specific antenatal interventions. ${ }^{32}$ Moreover, a further explanation of the results found in this study is that that birth weight is sensitive to environmental influences and the national level figures used in Leon and Moser's analysis will average out regional variations, as evidenced in the current paper, which focuses on mean birth weights specifically in Luton. ${ }^{140}$ Furthermore, these results fail to support the current explanation that South Asian infants are lighter as a consequence of their parents being of a smaller stature, ${ }^{194142}$ since BMI at booking and maternal height was controlled and adjusted mean birth weight was still found to be significantly lighter in all South Asian ethnicities, compared with WB.

While Patel and colleagues used a large South Asian sample size $(n=16$ 192) and found an increased OR for South Asian mothers having a preterm birth in their study, ${ }^{18}$ they aggregated Pakistani, Bangladeshi and Indian mothers, which obscured any subgroup trends. However, our study assessed preterm delivery in primipara Pakistani, Bangladeshi Indian and WB mothers and found a significant association between preterm delivery and Indian mothers, although it is recognised that socioeconomic factors were not controlled in this cohort.

MCS also showed that Indian mothers had a higher rate of preterm birth compared with Pakistani and Bangladeshi mothers; however, similar to the present study, the analyses was restricted to a binary outcome of births 24-37 weeks of gestation and after 37 weeks of gestation (hence excluding previable births). Therefore, this results in the loss of some information; exclusion of previable births (ie, <24 weeks of gestation) means that it is impossible to compare the frequency of early pregnancy loss by maternal ethnicity. ${ }^{12}$ Higher rates of early loss may well be evident in Pakistani mothers, due to a higher prevalence of congenital anomalies, some of which may be lethal, but this as yet needs to be elucidated. ${ }^{43}$
Taken together, these results highlight a number of key findings. First, that there are important differences between Pakistani, Bangladeshi and Indian infant birth weights, whereby treating them in research terms as a homogenous group categorised as 'South Asian' obscures distal determinants. Researchers should move away from using the category of 'South Asian' and be more specific about ethnicity when reporting populations under study. Second, when comparing the findings with previous studies, ${ }^{4121844}$ this study shows that the confounding variables controlled for also influences the results of which maternal ethnicity has the lightest mean birth weight, suggestive that a closer examination of maternal and behavioural mediators is warranted. It is possible that contributors for LBW in one population are less pronounced in another, and these factors need to be better understood. Furthermore, while there are known trends such as LBW in South Asian mothers, ${ }^{27} 28$ there are also clear ethnic and regional variations, suggestive of mediating social and environmental factors, which warrant further investigation.

This study has a number of strengths: the large sample sizes of the Indian, Pakistani and Bangladeshi mothers, compared with MCS, ${ }^{12}$ whereby the authors oversampled from black, Asian and minority ethnic populations, actually had smaller sample sizes from Indian $(n=433)$, Pakistani $(\mathrm{n}=687)$ and Bangladeshi mothers $(\mathrm{n}=215)$ than the present study, whose subgroup sample size is substantially larger, providing more generalisable results. In addition, it accesses 5 years' worth of data, which provides a more reliable picture and addresses any cohort anomalies that may occur in shorter duration datasets.

This study is not without limitations. Hypertension in pregnancy is known to contribute to growth restriction, placental problems and increase maternal mortality risk. However, in this cohort, the data reported only 12 cases; therefore, while this was excluded from analysis, it may have had a clinical impact not accounted for. Furthermore, while the sample sizes for Indian, Pakistani and Bangladeshi mothers were larger than MCS, our Indian sample size was still relatively small. In addition, there were no socioeconomic measures available to the research team to allow controlling of socioeconomic factors known to mediate preterm birth in this study. It would be beneficial for future research to investigate further trends in preterm birth and Pakistani, Bangladeshi and Indian infants, while controlling for socioeconomic factors, especially as there are known differences in the socioeconomic status between Indian, Pakistani and Bangladeshi ethnic groups in England. ${ }^{45}$

In conclusion, this study presents important differences in mean birth weights between Indian, Pakistani and Bangladeshi infants. Furthermore, an association between primipara Indian mothers and preterm birth was found. LBW and PTB both contribute significantly to mortality and morbidity outcomes; therefore, understanding the reasons for this disparity is essential for levelling up service provision and policy planning. ${ }^{20214647}$ 
Acknowledgements We would like to thank Martina McIntyre for extracting the de-identified data from CMiS and Tessa Pollard for her helpful comments on earlier drafts of this manuscript.

Contributors $R G$ and NA conceived the study; $M G$ assisted in identification of data, $R G$ and $A G$ conducted the statistical analyses, $R G, N A, G R, A G$ and $M G$ contributed to earlier drafts of the manuscript and all authors agreed the final version.

Funding The Steel Trust has provided funding to the University of Bedfordshire for RG to undertake research at Institute for Health Research, University of Bedfordshire, under the direction of NA and GR. The funders have no involvement in the research or publication.

Competing interests None declared.

Patient consent Secondary data were used.

Provenance and peer review Not commissioned; externally peer reviewed.

Data sharing statement № additional data are available.

Open Access This is an Open Access article distributed in accordance with the Creative Commons Attribution Non Commercial (CC BY-NC 4.0) license, which permits others to distribute, remix, adapt, build upon this work non-commercially, and license their derivative works on different terms, provided the original work is properly cited and the use is non-commercial. See: http://creativecommons.org/ licenses/by-nc/4.0/

(C) Article author(s) (or their employer(s) unless otherwise stated in the text of the article) 2017. All rights reserved. No commercial use is permitted unless otherwise expressly granted.

\section{REFERENCES}

1. Messer J. An analysis of the socio-demographic characteristics of sole registered births and infant deaths. Health Stat Q 2011:79-107.

2. Institute of Health Economics. Determinants and prevention of low birth weight : a synopsis of the evidence. Alberta, Canada, 2008.

3. De Farias Aragão VM, Barbieri MA, Moura Da Silva AA, et al. Risk factors for intrauterine growth restriction: a comparison between two Brazilian cities. Pediatr Res 2005;57:674-9.

4. Margetts BM, Mohd Yusof S, Al Dallal Z, et al. Persistence of lower birth weight in second generation South Asian babies born in the United Kingdom. J Epidemiol Community Health 2002;56:684-7.

5. Joshi KJ, Sochaliya KM, Shrivastav AV, et al. A hospital based study on the prevalence of low birth weight in newborn babies and its relation to maternal health factors. Int J Res Med 2014;3:4-8.

6. World Health Organisation. Promoting optimal fetal development: report of a technical consultation. Geneva, 2006. http://www.who.int/ nutrition/publications/fetal_dev_report_EN.pdf

7. Kramer MS. Determinants of low birth weight: methodological assessment and meta-analysis. Bull World Health Organ 1987;65:663-737 http://www.ncbi.nlm.nih.gov/pmc/articles/ PMC2491072/pdf/bullwho00076-0086.pdf

8. Escobar GJ, Littenberg B, Petitti DB. Outcome among surviving very low birthweight infants: a meta-analysis. Arch Dis Child 1991;66:204-11.

9. Blencowe H, Cousens S, Chou D, et al. Born Too Soon Preterm Birth Action Group. Born too soon: the global epidemiology of 15 million preterm births. Reprod Health 2013;10(Suppl 1):S2.

10. Lausman A, Kingdom J. Maternal-Fetal Medicine Committee. Intrauterine growth restriction: screening, diagnosis, and management. J Obstet Gynaecol Can 2013;35:741-8 http://sogc.org/ wp-content/uploads/2013/08/August2013-CPG295-ENG-Revised. pdf

11. Perinatal Institute for Maternal and Child Health. Intrauterine growth restriction,stillbirths and prevention. Prevalence of IUGR. $2011 \mathrm{http}: / /$ www.pi.nhs.uk/pnm/clinicaloutcomereviews/index.htm

12. Kelly $\mathrm{Y}$, Panico L, Bartley $\mathrm{M}$, et al. Why does birthweight vary among ethnic groups in the UK? Findings from the Millennium Cohort Study. $J$ Public Health 2009;31:131-7.

13. Jayaweera $H$, Joshi $H$, MacFarlane $A$, et al. Pregnancy and childbirth. In: Dex S, Joshi H, eds. Children of the 21 st century. Bristol: The Policy Press, 2005:109-33.

14. Leon DA, Moser KA. Low birth weight persists in South Asian babies born in England and Wales regardless of maternal country of birth. Slow pace of acculturation, physiological constraint or both? Analysis of routine data. J Epidemiol Community Health 2012;66:544-51.

15. Oldroyd J. Low birth weight in South Asian babies in Britain: time to reduce the inequalities. Fukushima J Med Sci 2005;51:1-10.
16. West J, Lawlor DA, Fairley L, et al. UK-born Pakistani-origin infants are relatively more adipose than white British infants: findings from 8704 mother-offspring pairs in the Born-in-Bradford prospective birth cohort. J Epidemiol Community Health 2013;67:544-51.

17. Dhawan S. Birth weights of infants of first generation Asian women in Britain compared with second generation Asian women. BMJ 1995;311:86-8 http://www.pubmedcentral.nih.gov/articlerender.fcgi? artid=2550148\&tool=pmcentrez\&rendertype=abstract

18. Patel RR, Steer $P$, Doyle $P$, et al. Does gestation vary by ethnic group? A London-based study of over 122,000 pregnancies with spontaneous onset of labour. Int J Epidemiol 2004;33:107-13.

19. Bansal N, Ayoola OO, Gemmell I, et al. Effects of early growth on blood pressure of infants of British European and South Asian origin at one year of age: the Manchester children's growth and vascular health study. J Hypertens 2008;26:412-8.

20. Hollowell J, Kurinczuk JJ, Brocklehurst P, et al. Social and ethnic inequalities in infant mortality: a perspective from the United Kingdom. Semin Perinatol 2011;35:240-4.

21. Zeitlin J, Szamotulska K, Drewniak N, et al. Euro-Peristat Preterm Study Group. Preterm birth time trends in Europe: a study of 19 countries. BJOG 2013;120:1356-65.

22. The National Institute for Health and Care Excellence. Maternal and child nutrition. $2010 \mathrm{http}: / / w w w . n i c e . o r g . u k / g u i d a n c e / p h 11 /$ resources/guidance-maternal-and-child-nutrition-pdf

23. Bansal N, Chalmers JW, Fischbacher CM, et al. Scottish Health and Ethnicity Linkage Study. Ethnicity and first birth: age, smoking, delivery, gestation, weight and feeding: Scottish Health and Ethnicity Linkage Study. Eur J Public Health 2014;24:911-6.

24. Han Z, Mulla S, Beyene J, et al. Knowledge Synthesis Group. Maternal underweight and the risk of preterm birth and low birth weight: a systematic review and meta-analyses. Int J Epidemiol 2011;40:65-101.

25. Loret de Mola C, de França GV, Quevedo LA, et al. Low birth weight, preterm birth and small for gestational age association with adult depression: systematic review and meta-analysis. Br J Psychiatry 2014;205:340-7.

26. Office for National Statistics. Statistical Bulletin Births in England and Wales by Parents' Country of Birth: 2013, 2014.

27. Harding S, Rosato MG, Cruickshank JK. Lack of change in birthweights of infants by generational status among Indian, Pakistani, Bangladeshi, Black Caribbean, and black African mothers in a British cohort study. Int J Epidemiol 2004;33:1279-85.

28. Moser K, Stanfield KM, Leon DA. Birthweight and gestational age by ethnic group, England and Wales 2005: introducing new data on births. Health Stat Q 2008;31:34-55 http://webarchive. nationalarchives.gov.uk/20160105160709/http://www.ons.gov. uk/ons/rel/hsq/health-statistics-quarterly/no-39-autumn-2008/ birthweight-and-gestational-age-by-ethnic-group-england-andwales-2005.pdf

29. Office for National Statistics. Statistical Bulletin Childhood, Infant and Perinatal Mortality in England and Wales, 2012, 2012. http://www. ons.gov.uk/ons/rel/vsob1/child-mortality-statistics-childhood-infantand-perinatal/2012/

30. Kent ST, McClure LA, Zaitchik BF, et al. Area-level risk factors for adverse birth outcomes: trends in urban and rural settings. BMC Pregnancy Childbirth 2013;13:129.

31. Yadav H, Lee N. Maternal factors in predicting low birth weight babies. Med J Malaysia 2013;68:44-7.

32. Garcia R, Ali N, Papadopoulos C, et al. Specific antenatal interventions for Black, Asian and Minority Ethnic (BAME) pregnant women at high risk of poor birth outcomes in the United Kingdom: a scoping review. BMC Pregnancy Childbirth 2015;15:226.

33. Kim D, Saada A. The social determinants of infant mortality and birth outcomes in Western developed nations: a crosscountry systematic review. Int $J$ Environ Res Public Health 2013;10:2296-335.

34. Cresswell JA, Yu G, Hatherall B, et al. Predictors of the timing of initiation of antenatal care in an ethnically diverse urban cohort in the UK. BMC Pregnancy Childbirth 2013;13:103 http://www. pubmedcentral.nih.gov/articlerender.fcgi?artid=3652742\&tool= pmcentrez\&rendertype $=$ abstract

35. Ravelli AC, Tromp M, Eskes M, et al. Ethnic differences in stillbirth and early neonatal mortality in the Netherlands. J Epidemiol Community Health 2011;65:696-701.

36. Freemantle N, Wood J, Griffin C, et al. What factors predict differences in infant and perinatal mortality in primary care trusts in England? A prognostic model. BMJ 2009;339:b2892.

37. Silverwood RJ, Pierce M, Hardy R, et al. Low birth weight, later renal function, and the roles of adulthood blood pressure, diabetes, and obesity in a British birth cohort. Kidney Int 2013;84:1262-70. 
38. Department of Health. Data standards: ethnic category. 2008 http:// webarchive.nationalarchives.gov.uk/+/http://www.isb.nhs.uk/ documents/dscn/dscn2008/dataset/112008.pdf

39. Economic and Social Data Service. Ethnicity: introductory user guide. 2012 http://www.esds.ac.uk/government/docs/ethnicityintro. pdf

40. Enkin M, Chalmers I. Effectiveness and satisfaction in antenatal care In: Enkin U, Chalmers I, eds. Antenatal Care. London: Heinemann Medical, 1982:266-90.

41. Sachdev HPS. Low birth weight in South Asia. International Journal of Diabetes in Developing Countries 2001;21:13-31.

42. Clarson CL, Barker MJ, Marshall T, et al. Secular change in birthweight of Asian babies born in Birmingham. Arch Dis Child 1982;57:867-71.

43. Kurinczuk JJ, Hollowell J, Boyd PA, et al. The contribution of congenital anomalies to infant mortality, 2010.
44. Leon DA, Moser KA. Low birth weight persists in South Asian babies born in England and Wales regardless of maternal country of birth. Slow pace of acculturation, physiological constraint or both? Analysis of routine data. J Epidemiol Community Health 2012;66:544-51.

45. Platt L. Inequality within ethnic groups. 2011 http://www.jrf.org.uk/ sites/files/jrf/inequality-ethnicity-poverty-full.pdf

46. Whitehead M, Dahlgren G. Concepts and principles for tackling social inequities in health : levelling up part 1: World Health Organization, 2007:1-45. http://www.euro.who.int/ data/assets/pdf file/0010/ 74737/E89383.pdf

47. Dahlgren G, Whitehead M. European strategies for tackling social inequities in health: levelling up part 2: World Health Organisation, 2007. http://www.euro.who.int/_data/assets/pdf_file/0018/103824/ E89384.pdf 